\title{
Novel placement of an esophageal wound vacuum for a persistent anastomotic leak
}

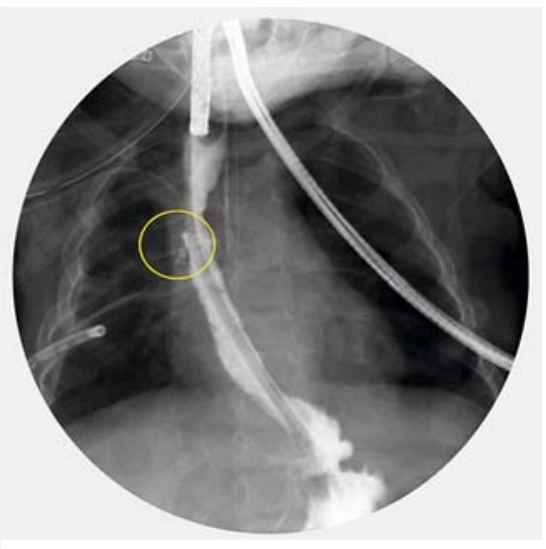

- Fig. 1 Esophagram before the wound vacuum therapy showing an esophageal leak.

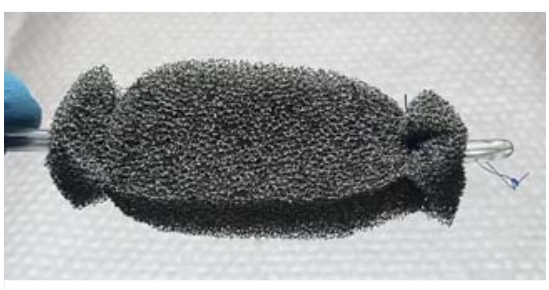

$\checkmark$ Fig. 2 Photograph of the completed wound vacuum device prior to placement.

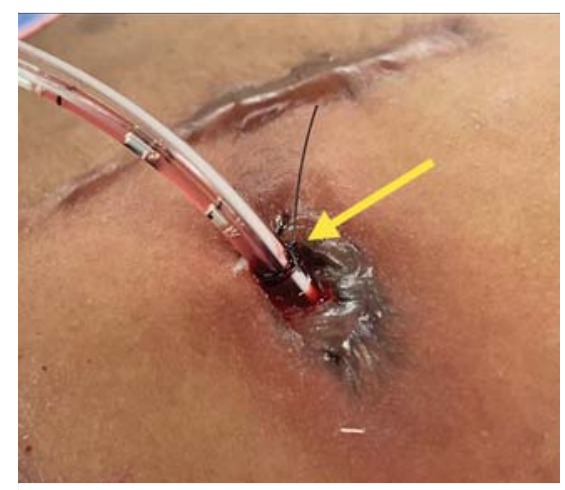

-Fig. 3 Photograph following placement of the wound vacuum device showing the gastrostomy site suture placed for tube stabilization.

Esophageal vacuum-assisted closure is a relatively new technique that has been offered as an alternative to stenting. A recent study by Manfredi et al. demon-

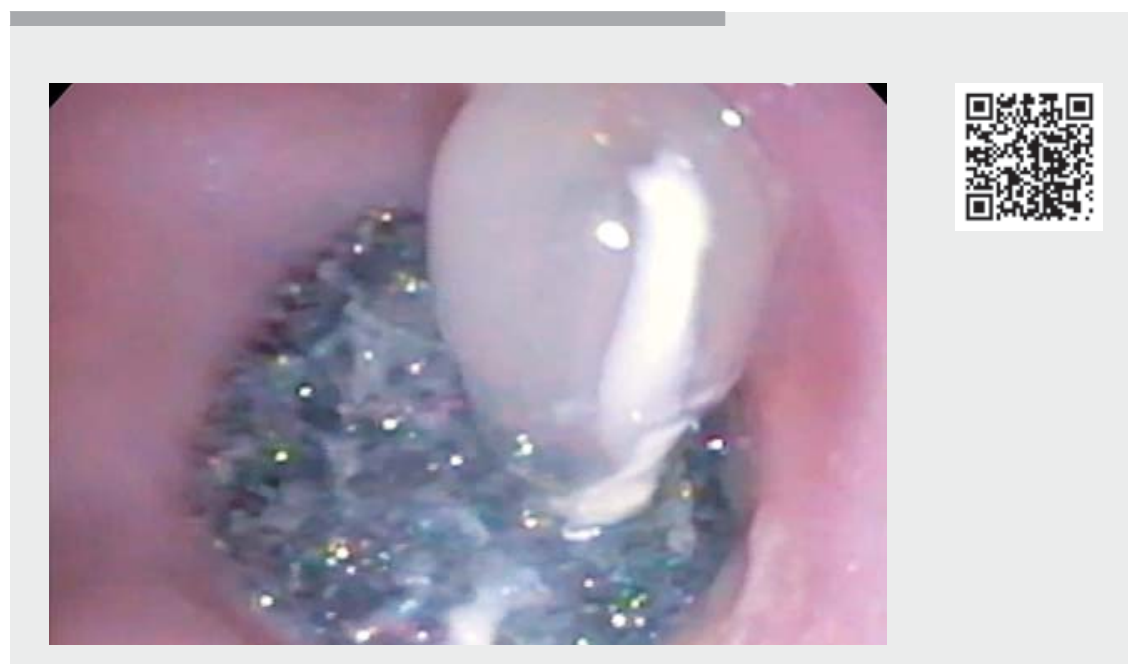

$\square$ Video 1 Novel placement of an esophageal wound vacuum for persistent anastomotic leak.
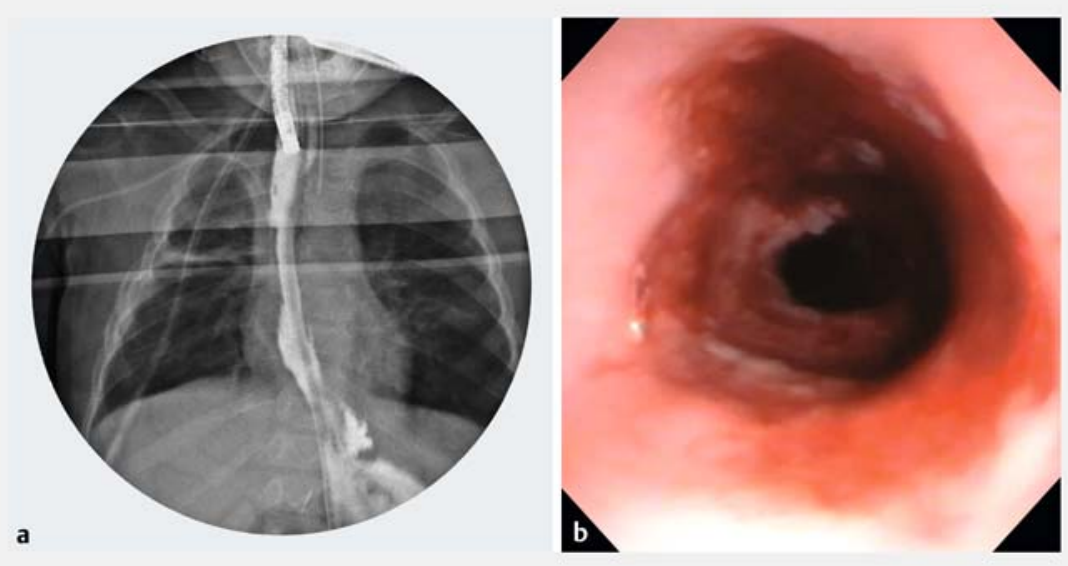

Fig. 4 Appearances after the wound vacuum therapy on: a esophagram; b endoscopic inspection.

strated the efficacy of this therapy in pediatric patients [1]. We present our experience using this therapy to resolve a persistent esophageal perforation.

A 20-month-old girl with a past medical history of tracheoesophageal fistula and esophageal atresia was noted to have a persistent leak after revision of the anastomosis ( Fig. 1). A capture loop was created on a 14-Fr sump tube using a non-absorbable suture. Given the patient had a gastrostomy tube in place, a retrograde approach was used. The sump tube was inserted into the gastrostomy, captured with a forceps, and pulled into the esophagus. Assembly of the device occurred on the patient's chest ( $\mathbf{F i g . 2}$ ). The sponge was then positioned by pulling on the tubing at the gastrostomy. The wound vacuum 
was activated after connection of the tubing, using settings of $125 \mathrm{mmHg}$ at continuous moderate intensity [1]. A single suture was placed at the gastrostomy site to secure the tubing ( $\mathbf{F i g . 3}$; - Video 1).

In the postoperative period, the patient was noted to have signs of intolerance of secretions. Her symptoms improved with a change of the wound vacuum settings to intermittent ( 5 minutes on, 2 minutes off). Re-evaluation occurred after a 5-day period. A cold snare was used to capture the device after the capture loop was not visualized. A repeat esophagram demonstrated resolution of the leak ( $\triangleright$ Fig.4). The patient recovered without complications and was discharged on post-op day 3 .

Previous studies have demonstrated the efficacy of esophageal wound vacuums for the healing of perforations in both adults and children [1-4]. Initial results have shown superiority to stenting with regards to the length of therapy [1]. Our case again demonstrates the efficacy of the technique, but further prospective studies will be needed to reinforce these findings.

Endoscopy_UCTN_Code_TTT_1AO_2AI

\section{Competing interests}

The authors declare that they have no conflict of interest.
The authors

Jonathan Wong' ${ }^{1}$, Dave Lal' ${ }^{2}$, Jack Schneider ${ }^{2}$, Ali Mejaddam ${ }^{2}$, Michael Manfredi ${ }^{3}$, Diana

Lerner $^{1}$

1 Division of Pediatric Gastroenterology, Hepatology and Nutrition, Department of Pediatrics, Medical College of Wisconsin, Milwaukee, Wisconsin, USA

2 Division of Pediatric Surgery, Department of Surgery, Medical College of Wisconsin, Milwaukee, Wisconsin, USA

3 Esophageal and Airway Atresia Treatment Center, Boston Children's Hospital, Boston, Massachusetts, USA

\section{Corresponding author}

\section{Jonathan Wong, DO}

Division of Gastroenterology, Hepatology and Nutrition, Department of Pediatrics, Medical College of Wisconsin, 8701 Watertown Plank Road, Milwaukee, WI 53226, USA

Fax: +1-414-266-8495

jwong@mcw.edu

\section{References}

[1] Manfredi M, Clark S, Staffa S et al. Endoscopic esophageal vacuum therapy: A novel therapy for esophageal perforations in pediatric patients. J Pediatr Gastroenterol Nutr 2018; 67: 706-712

[2] Schorsch T, Müller C, Loske G. Endoscopic vacuum therapy of anastomotic leakage and iatrogenic perforation in the esophagus. Surg Endosc 2013; 27: 2040-2045
[3] Kuehn F, Schiffmann L, Janisch F et al. Surgical endoscopic vacuum therapy for defects of the upper gastrointestinal tract. J Gastrointest Surg 2016; 20: 237-243

[4] Laukoetter M, Mennigen R, Neumann P et al. Successful closure of defects in the upper gastrointestinal tract by endoscopic vacuum therapy (EVT): a prospective cohort study. Surg Endosc 2017; 31: 2687-2696

\section{Bibliography}

Endoscopy 2021; 53: E388-E389

DOI 10.1055/a-1308-1007

ISSN 0013-726X

published online 17.12 .2020

(c) 2020. Thieme. All rights reserved.

Georg Thieme Verlag KG, Rüdigerstraße 14,

70469 Stuttgart, Germany

ENDOSCOPY E-VIDEOS

https://eref.thieme.de/e-videos

回回 Endoscopy E-Videos is a free access online section, reporting 靣辌: on interesting cases and new techniques in gastroenterological endoscopy. All papers include a high quality video and all contributions are freely accessible online.

This section has its own submission website at https://mc.manuscriptcentral.com/e-videos 